Marquette University

e-Publications@Marquette

College of Nursing Faculty Research and

Publications

Nursing, College of

$1-1-2011$

\title{
Psychometric Properties of a Measure of Acceptance of Long-Standing Health Problems
}

Patricia McDonald

Case Western Reserve University

Jaclene Zauszniewski

Case Western Reserve University

Abir K. Bekhet

Marquette University, abir.bekhet@marquette.edu

Accepted version. Issues in Mental Health Nursing, Vol. 32, No. 7 (July 2011): 416-423. DOI. (C) 2011 Informa Healthcare. Used with permission. 


\title{
Psychometric Properties of a Measure of Acceptance of Long- Standing Health Problems
}

\author{
Patricia E. McDonald, PhD, RN ${ }^{1}$ [Assistant Professor of Nursing], Jaclene A. Zauszniewski, \\ PhD, RN-BC, FAAN ${ }^{1}$ [Kate Hanna Harvey Professor in Community Health Nursing], and \\ Abir K. Bekhet, PhD, RN, H.S.M.I. ${ }^{2}$ [Assistant Professor] \\ ${ }^{1}$ Frances Payne Bolton School of Nursing, Case Western Reserve University, Cleveland, $\mathrm{OH}$ \\ 44106-4904 \\ ${ }^{2}$ Marquette University College of Nursing, Milwaukee, WI, 53220
}

\begin{abstract}
Acceptance of chronic illness is important for health promotion and for improving the quality of life of elders with chronic conditions. Thus, a reliable and valid measure of acceptance is needed for this population. Currently available measures of acceptance do not focus specifically on accepting chronic conditions. This study of 176 elders with chronic conditions examined the psychometric properties of an adapted measure of acceptance - the Ideas about Long-standing Health Problems (IALHP) questionnaire. Although the findings provided beginning evidence for internal reliability and construct validity to support its potential usefulness in elders, further scale development is recommended.
\end{abstract}

\section{Keywords}

Acceptance; Chronic Conditions; Older Adults; Reliability; Validity

The rapidly expanding numbers of older adults in the U. S. pose numerous challenges related to their increased vulnerability to chronic illness (Wagner, et al., 2001). About 75\% of adults aged 65 years and older have at least one chronic disease (Ko \& Coons, 2005), and $50 \%$ have two or more (Wolff, Starfield, \& Anderson, 2002). Approximately half of aged people are not capable of performing some daily activities; further, they suffer from anxiety, depression, and declines in physical functioning (Dunlop, Manheim, Sohn, Liu, \& Chang, 2002; Miller, et al., 2004). While 74\% of White and 58\% of Black elders have reported their health as better than good (Lee, et al., 2007), this may reflect reluctance to acknowledge the full extent of their limitations due to chronic conditions or by comparison they feel that others are worse off (Silverman, Nutini, Musa, Schoenberg, \& Albert, 2009).

Acceptance is an active process in which persons acknowledge their thoughts, feelings, and memories (Hayes, 1994). Acceptance has been described as "a present-oriented activity requiring energy and characterized by receptivity toward and satisfaction with someone or something, including past circumstance, present situations, others, and ultimately the self" (Haase, Britt, Coward, Leidy, \& Penn, 1992, p. 144). Acceptance of chronic illness is

Address correspondence to: Patricia E. McDonald, PhD, RN, Bolton School of Nursing, Case Western Reserve University, 10900 Euclid Avenue, Cleveland, OH 44106, Phone: 216-368-3345, Fax: 216-368-3542, pxm9@ case.edu. Alternate correspondence to: Jaclene A. Zauszniewski, PhD, RN-BC, FAAN, Bolton School of Nursing, Case Western Reserve University, 10900 Euclid Avenue, Cleveland, OH 44016, Phone: 216- 368-3612, Fax: 216-368-3542, jaz@ case.edu. 
conceptualized as the desire to take possession of one's illness (McDonald, Wykle, Misra, Suwannaroop, \& Burant, 2002).

When elderly persons experience long-standing health problems, their lifestyles have to change. This might result in a crisis and the changes require enormous strength to maintain equilibrium. However, acceptance of their chronic health conditions may be helpful in managing chronic illness (Linkowski, 1971). Studies have found, for example, that diabetic patients who showed greater acceptance of their conditions had higher coping capabilities (Richardson, Adner, \& Nordstrom, 2001; Telford, Kralik, \& Koch, 2006) and experienced greater satisfaction (Dion, 1990). A qualitative study of six asthmatic adolescents by Kintner (1997) identified the process of acceptance as including awareness, acknowledgement, acquisition of knowledge, resignation, reasoning, reaching of conclusions, and finally, acceptance by taking control of the asthma. According to Haase and colleagues (1992), acceptance can facilitate personal growth, manifested as increased self-worth and selfawareness; and Stuifbergen and Rogers (1997), using a phenomenological approach, found that acceptance was an antecedent to health promotion and improved quality of life for persons with chronic and disabling conditions. Acceptance of chronic conditions has received some attention in previous studies (Dion, 1990; Richardson et al., 2001; Stuifbergen, Blozis, \& Beal, 2008; Telford et al., 2006). However, the instruments used in those studies were developed to measure acceptance of specific chronic health problems. Yet, older adults commonly experience multiple chronic conditions (McDonald, Zauszniewski, \& Bekhet, 2010; Silverman, Nutini, Musa, Schoenberg, \& Albert, 2009). Thus, a measure that captures multiple conditions experienced by elders, such as the one described in this manuscript, is needed.

\section{Development of the IALHP}

The Ideas about Long-standing Health Problems (IALHP) questionnaire [examined in this study] was adapted from the Ideas about Diabetes-Revised (IAD-R) questionnaire [the original measure] developed by Dion (1990). The IALHP questionnaire is useful because it measures a broad spectrum of chronic conditions experienced by older adults and is not limited to one primary condition. Moreover, the measure can be used in multiple clinical, community, and research settings. Permission was granted to modify the IAD-R by replacing the word "diabetes" with the words "longstanding health problem." The IALHP contains 20 statements measuring acceptance of the implications of having long-standing health problems. Respondents are asked to indicate whether they agree with these statements or not on a 5-point Likert scale ranging from strongly agree (4) to strongly disagree (0). Eight items out of the 20 are phrased in a negative direction. A high composite score after reversing those items indicates greater acceptance (Dion, 1990). The original IAD-R has acceptable psychometric properties; internal consistency estimates (Cronbach's) of the IAD$\mathrm{R}$ ranged from .87 to .91 in previous studies (Dion, 1990), and content validity of the scale was supported by ten experts in the area of diabetes. Factor analysis indicated three dimensions of accepting diabetes: outlook, confidence, and inhibitors (Dion, 1990). This factor analysis showed there were 7 items on the outlook subscale, 6 on the confidence subscale, and 6 on the inhibitors subscale. One item, which addressed not telling others about one's health problems, was considered a "filler" item and it did not load on any of the three subscales. Correlations among these factors were reported to be between .30 and .70 . However, several items on the IAD-R were found to have significant loadings on more than one factor (Dion, 1990).

In this study, the psychometric properties of the IALHP, an adapted measure of acceptance, were examined. We evaluated estimates of internal consistency of the full scale and three subscales identified by Dion (1990) for the About Diabetes-Revised (IAD-R). We also 
assessed inter-item, item to subscale and total scale, and subscale to total scale correlations and performed an exploratory factor analysis to verify the presence of Dion's three factors found in the IAD-R questionnaire. Finally, to establish construct validity, we examined associations between the IALHP and measures of theoretically-related constructs including self-assessed health, functional status, anxiety, depression, and positive cognitions.

\section{Methods}

\section{Design and Sample}

This study used a cross-sectional, descriptive design to examine the psychometric properties of an adapted measure of acceptance - - the 20-item Ideas about Long-standing Health Problems (IALHP) questionnaire. The study was part of a larger, longitudinal study of elders that has been reported elsewhere (Zauszniewski, et al., 2004; Zauszniewski, Morris, Preechawong, \& Chang, 2004). The convenience sample included 176 elders aged 64-96 years, with an average age of 83 years. All resided in a retirement community and received services or assistance with at least one of the activities of daily living including ambulation, toileting, meal preparation, shopping, and housework; none were cognitively impaired, as determined by a score of 6 or lower on the 10-item Short Portable Mental Status Questionnaire (SPMSQ) (Pfeiffer, 1975).

The sample included 139 females (79\%) and 37 males (21\%). The majority were Caucasian (90.3\%); 16 were African-American, and only one was American-Indian. On average, the elders reported three chronic conditions; the most common were arthritis (68.2\%), high blood pressure $(54.3 \%)$, heart trouble $(39.4 \%)$, circulation problems $(30.8 \%)$, and urinary tract disorders $(23.6 \%)$. Other reported chronic conditions included gastrointestinal problems $(17.0 \%)$, diabetes $(16.0 \%)$, glaucoma $(12.6 \%)$, thyroid disorders $(12.6 \%)$, and effects of stroke (11.6\%). Nearly 10\% reported respiratory problems (asthma, 9.7\%; emphysema/bronchitis, $9.1 \%$ ). Anemia was reported by $9.7 \%$, skin disorders were reported by $7.4 \%$, and cancer was reported by $6.9 \%$ of the study participants. Less than $5 \%$ of the study participants reported digestive disorders/ulcers (4.7\%), kidney disease (2.8\%), Parkinson's disease (2.3\%), liver disease (1.1\%), and epilepsy (0.6\%).

\section{Instruments}

The IALHP questionnaire, which is an adapted measure of the Ideas about Diabetes-Revised (IAD-R) questionnaire, was administered along with a demographic questionnaire, a questionnaire on the number and type of chronic conditions developed by Fillenbaum (1988), and measures of theoretically-related constructs (self-assessed health, positive cognitions, depression, anxiety, and functional status), which were used for construct validation.

The rationale for selecting the validating constructs is rooted in self-regulation theory where acceptance may be viewed as an emotion-regulation strategy that is protective against psychopathology (Aldao, Nolen-Hoeksema, \& Schweizer, 2010), which can be manifested in symptoms of depression or anxiety (Bussing, Mathiessen, \& Mundle, 2008). The common sense theory of self-regulation theory (Hale, Treharne, \& Kitas, 2007) suggests that an individual's beliefs and expectations about illness, which reflect what the illness represents or means to that person (i.e. self-assessed health), determines his or her cognitive appraisal of the situation (i.e. positive or negative cognitions) and affects behavior, including the ability to function in daily activities (i.e. functional status).

Self-assessed health was measured by three items that asked participants to rate their physical health as excellent $=4$, good $=3$, fair $=2$, or poor $=1$; to rate their health in 
comparison to their peers as worse $=1$, the same $=2$, or better $=3$; and to rate the extent to which their health interfered with daily activities, as not at all $=1$, some interference $=2$, or extremely bothersome $=3$. Individual scores were first standardized and then summed for a total score; higher scores indicated better self-assessed health. Subjective measures of perceived health have been widely used in studies of older adults and the results indicate that self-rated health is a reliable and valid substitute for objective measures (Ferri, James, \& Pruchno, 2009).

Positive cognitions were measured by the Depressive Cognition Scale (DCS) developed by Zauszniewski (1995), which captures positive cognitions when scores are not reversed. On this 8-item instrument, subjects use a 6-point Likert scale ranging from strongly agree (5) to strongly disagree $(0)$ to indicate the degree to which a particular statement describes their current thoughts (Zauszniewski, 1995). Each item reflects one positive cognition (e.g., hope, worth, etc.). Strong agreement with a particular DCS item indicates the presence of a specific positive cognition. Scores may range from 0 to 40 and, a higher composite score indicates a greater number of positive cognitions. Construct validity of the DCS has been assessed with a variety of populations, including community dwelling older adults (Bekhet, Zauszniewski, \& Wykle, 2008; Zauszniewski, 1995), healthy elders (1997), women with type 2 diabetes (Zauszniewski, Chung, Krafcik, \& Sousa, 2001), and African-American women (Zauszniewski, Picot, Debanne, Roberts, \& Wykle, 2002). Internal consistency reliabilities of this scale have ranged from .78 to .87 in previous studies (Zauszniewski, 1997; Zauszniewski, Chung, Krafcik, \& Sousa, 2001; Bekhet et al., 2008).

Depressive symptoms were measured by the Center for Epidemiological Studies-Depression Scale (CES-D). The 20-item CES-D (Radloff, 1977) asks participants to rate the frequency with which they experienced each listed symptom during the week prior to the interview on a 4-point Likert-type scale ranging from "rarely or none of the time" (0) to "most or all of the time" (3). Scores range from 0 to 60; higher scores after reverse coding of four items indicate greater frequency of depressive symptoms. The cutoff of the CES-D scale for clinical depression is 16 . The scale is a widely reported valid measure, and it has been standardized for a variety of ages and racial groups (Mui, Burnette, \& Chen, 2001). Alpha coefficients of .87 for elders with diabetes (Zauszniewski \& Graham, 2009) and .84 for elderly women with chronic conditions (Zauszniewski \& Bekhet, 2009) have been reported.

Anxiety was measured by the State Anxiety Inventory (STAI A-State) (Spielberger, 1983). The STAI is a 20-item scale measuring current anxiety; subjects rate the degree to which the items describe current feelings on a 4-point Likert-type scale ranging from "very much so" to "not at all." Scores range from 20 to 80; higher scores after reverse coding indicate more anxiety. The scale has been widely used with diverse populations, including older adults. Psychometric properties including construct, predictive and concurrent validity, stability, and internal consistency reliability have been widely reported. Estimates of internal consistency reliability for the STAI in elders have ranged from .79 to .94 and evidence of its discriminant validity has been reported (Dennis, Boddington, \& Fennell, 2007).

Functional status was measured by the Health Assessment Questionnaire (HAQ) (Fries, 1980/1996). The HAQ includes 19 questions related to functioning during the past week. These questions cover eight areas: dressing and grooming, arising, eating, walking, hygiene, reaching, gripping, and outdoor activities. Each component includes 2-3 questions; responses are scored on a 4-point scale of functional ability ranging from "without any difficulty" to "unable to do." The highest scores for the eight components are added for a total score ranging from 0 to 24 , with higher scores reflecting higher levels of disability. The HAQ has been widely used, and considerable evidence of reliability and validity is available in existing literature (Bruce \& Fries, 2003). 


\section{Data Collection Procedures}

Approval from the Institutional Review Board was obtained prior to data collection. The participants were individually interviewed by trained data collectors in a private setting at a time that was mutually agreed upon. During the interview, information on age, gender, race, and number and types of chronic conditions was obtained, and participants completed the self-assessed health, DCS, and IALHP measures.

\section{Results}

\section{Reliability Estimates}

The internal consistency estimate (Cronbach's alpha) for the IALHP total sample ( $\mathrm{N}=176)$ was .83 , indicating acceptable internal consistency based on the criterion of .70 or above (Nunnally \& Bernstein, 1994). In addition, internal consistency estimates for the three subscales identified by Dion (1990) in the adapted IALHP Scale were $.80, .58$, and .76 for the outlook, confidence, and inhibitors to acceptance subscales, respectively (Table 1). Thus, the alpha coefficients for two subscales-outlook and inhibitors met the criteria for acceptable internal consistency (Nunnally and Bernstein, 1994). However, the lower alpha (. 58) obtained for the confidence subscale failed to meet the minimum criterion for internal consistency.

Reliability of the IALHP was also evaluated by examining inter-item correlations. Nunnally and Bernstein (1994) suggested that inter-item correlations should average between .30 and . 70 and correlations above .70 indicate redundancy. In this study, the average inter-item correlation without the filler item was .21. This low average inter-item correlation suggests that the items constituting the IALHP are measuring diverse aspects of acceptance, perhaps supporting the existence of the three dimensions.

Item to subscale correlations were examined to ascertain the homogeneity of subscales comprising the IALHP (Table 2). Of the 6 items on the inhibitors subscale, 3 fell within the desired range and 3 exceeded the .70 criteria. Of the 6 items on the confidence subscale, 4 fell within the desired range and 2 exceeded the .70 criteria. Of the 7 items on the outlook subscale, 4 fell within the desired range and 3 exceeded the .70 criteria.

Item to total scale correlations were examined to determine the homogeneity of the IALHP instrument (Table 2). Excluding the one filler item, 16 IALHP items had correlations with the total scale that fell within the desired rage ( .30 to .70$)$. Two items fell below the .30 criteria and one exceeded the .70 criteria. Eighteen of the 20 items had significant correlations $(\mathrm{p}<.01)$ with the total scale. However, two items, including the filler item and the confidence item addressing talking about health problems, did not correlate with the total acceptance scale.

In addition, we examined the correlations between each item and the subscale that it was expected to reflect (Table 2). All of the items correlated significantly with their respective subscales; item to subscale correlations ranged from .34 to .81 . However, there were eight items with correlations that exceeded the suggested .70 criteria. Two items were from the confidence subscale, and three each from the outlook and inhibitors subscales. Finally, correlations between the three subscales and the total scale were examined (Table 1). Two of the subscales, outlook and inhibitors, had correlations with the total scale that exceeded the . 70 criteria while the confidence subscale correlation with the total scale fell within the desired range. 


\section{Validity Estimates}

Factor analysis was used to examine the construct validity of the IALHP. However, before conducting the factor analysis, the adequacy of the sample and data were examined in relation to specific statistical parameters (Strickland, 2003). The KMO index of .829 indicated sampling adequacy (Kaiser, 1974), and Bartlett's test of sphericity $\left(X^{2}(190, \mathrm{n}=\right.$ $176)=1127.98$; determinant $=.001)$ indicated that the correlation matrix was suitable for factor analysis (Strickland, 2003). Having met the conditions of adequate sample size and suitability of the correlation matrix, the data from the 20-item IALHP scale were subjected to factor analysis using the maximum likelihood method of factor extraction and forcing the items onto three factors, as suggested by Dion (1990). Because the low average inter-item correlation found on the IALHP scale suggested the three factors may not be correlated (orthogonal), varimax rotation was used. In addition, the scree plot (Figure 1) supported the selection of three factors, which accounted for $37.8 \%$ of the total variance. In general, scree plots are graphical representations of the eigenvalues of the scale items in descending order; the graph is interpreted by determining the point at which the line begins to flatten and additional factors are considered as trivial (Ledesma, \& Valero-Mora, 2007).

Twelve of the 20 items (60\%) loaded significantly on the predicted factor. Two items crossloaded on both the outlook and inhibitors subscales. Three confidence items loaded on the outlook subscale. There was one inhibitor, one confidence, and the one filler items that did not load on any of the three factors. However, the goodness of fit index $\left(X^{2}(133, \mathrm{n}=176)=\right.$ $219.12 ; p<.001)$ suggested that the 3 -factor model did not fit the data well; further exploratory analyses revealed that models with six or more factors would provide a better fit to the data. Factor loadings for the three factors are shown in Table 3.

Twelve of the 20 items (60\%) loaded significantly on the predicted factor. Nine items loaded on Factor I, which accounted for $45 \%$ of the common variance and $16.9 \%$ of the total variance (Table 1). Examination of these items indicated that $67 \%(\mathrm{~N}=6)$ represented outlook, 33\% represented confidence $(\mathrm{N}=3)$, and none represented inhibitors to acceptance. Six items loaded on Factor II, which accounted for 36\% of the common variance and $13.5 \%$ of the total variance. Five of the six items $(83 \%)$ reflected inhibitors to acceptance while one item $(17 \%)$ reflected outlook. However, the outlook item and one inhibitor item crossloaded on Factor 1, which appeared to capture outlook. Two items loaded on Factor III, which accounted for $19 \%$ of the common variance and $7.4 \%$ of the total variance. These two items measured confidence. As shown in Table 3, three items did not load on any of the three factors, including one inhibitor item, one confidence item, and the one filler item. Interestingly, two of the items that failed to load on any factor, including the filler item and one confidence item, addressed not talking about health problems. Yet, the two items that load on Factor 3, which appear to reflect confidence, also addressed talking about health problems. Thus, it seems that confidence is integrally associated with communicating about one's health.

In addition, construct validity was supported by significant correlations between IALHP and measures of theoretically-related constructs (Table 4). Acceptance was strongly correlated with self-assessed health $(r=.53, \mathrm{p}<.001)$ and positive cognitions $(r=.61, \mathrm{p}<.001)$ in the positive direction and moderately correlated with functional status $(\mathrm{r}=-.53, \mathrm{p}<.001)$, anxiety $(\mathrm{r}=-.39, \mathrm{p}<.001)$, and depression $(\mathrm{r}=-.44, \mathrm{p}<.001)$ in the negative direction.

\section{Discussion}

This psychometric investigation is the first reported analysis of the reliability and validity of the measure of acceptance of long-standing health problems among the elderly. Reliability of the IALHP scale was demonstrated by an alpha coefficient of .83, similar to the 
Cronbach's alphas reported in previous studies (Dion, 1990; Zauszniewski, McDonald, Krafcik, \& Chung, 2002).

Internal consistency estimates for the three subscales of the IALHP had not been previously examined. In this study, there were acceptable alpha coefficients for two of three subscales (outlook and inhibitors); the low alpha (.58) on the confidence subscale failed to meet the minimum criteria for acceptable internal consistency. Of note, the emergence of the three subscales from the IADR was not strongly supported in this study for a couple of reasons. First, the model fit was not $\operatorname{good}\left(X^{2}(133, \mathrm{n}=176)=219.12 ; p<.001\right)$, In fact, the goodness of fit index suggested that the three factors did not fit the data well. The second reason is the low alpha on the confidence subscale. Therefore, further exploratory analyses with more factors may provide a better fit to the data. Further scale development is recommended as well as further examination of the psychometric properties of the IALHP and the subscales with other populations.

Item to subscale correlations revealed that there were three items on inhibitors subscale, two items on confidence subscale, and three on outlook subscale exceeding the .70 criteria indicating redundancy of the items and suggesting further scale development. Moreover, two of the subscales, outlook and inhibitors, had correlations with the total scale that exceeded the .70 criteria suggesting the need for further scale development.

Construct validity was supported in this study by significant correlations between IALHP and measures of theoretically-related constructs. Acceptance was strongly correlated with self-assessed health and positive cognitions in the positive direction. There is some evidence that acceptance plays a significant role in promoting well-being in elders. Ranzijn and Luszcz (1999) noted that acceptance is important for older people to maintain their wellbeing because they must accept age-related change as a normal process. The significant relations found in this study between the measure of acceptance of chronic conditions, selfassessed health, and positive cognitions are indicators of the construct validity of the IALHP. A previous study of persons with diabetes (McDonald, et al. 2002) also found significant correlations between acceptance of diabetes and physical functioning and mental health. Furthermore, in a qualitative study of elders' perception of formal and informal care, Roe, Whattam, Young and Dimond (2001) identified three styles of adjustment within their data: positive, resigned, and passive acceptance.

Maximum likelihood analysis with varimax rotation showed that twelve of the 20 items loaded significantly on the predicted factors reflecting three theoretical components of acceptance (outlook, confidence, and inhibitors). Yet all items did not cluster as expected. The IALHP appears to be a useful measure of acceptance of chronic conditions, but further investigation of its psychometric properties is recommended.

Of interest, two of the items that failed to load on any factor, including the filler item and one confidence item, addressed not talking about health problems. Yet, the two items that load on Factor 3, which appear to reflect confidence, also addressed talking about health problems suggesting that "talking about health problems" is a means of acceptance. Apparently, many of the scale items tapping this idea are suggesting another separate factor addressing "talking about health problems".

In conclusion, the findings from this analysis of the psychometric properties of the measure of acceptance of long-standing health problems among the elderly yield promising initial evidence that the scale has acceptable reliability and validity and is potentially useful for assessing acceptance of long-standing health problems among older adults. The findings also indicate that the measure can be used in clinical and community settings. 
Further psychometric testing of the scale may be warranted. Some items may need to be eliminated to overcome redundancy, improve scale alpha, and to improve replication of the 3 -factors of Dion's original IAD-R questionnaire. Further psychometric testing of the IALHP scale is needed to optimize its reliability and validity for older adults with multiple chronic conditions. Given the fact that the majority of the sample were Caucasian (90.3\%), further testing in diverse populations is recommended so that the measure can have more widespread use in research and clinical practice.

\section{References}

Aldao A, Nolen-Hoeksema S, Schweizer S. Emotion-regulation strategies across psychopathology: A meta-analytic review. Clinical Psychology Review. 2010; 30:217-237. [PubMed: 20015584]

Bekhet A, Zauszniewski J, Wykle M. Milieu change and relocation adjustment in elders. Western Journal of Nursing Research. 2008; 30(1):113-129. [PubMed: 18029543]

Bruce B, Fries JF. The Stanford Health Assessment Questionnaire: A review of its history, issues, progress, and documentation. Rheumatologica Historica. 2003; 30(1):167-178.

Bussing A, Mathiessen PF, Mundle G. Emotional and rational disease acceptance in patients with depression and alcohol addiction. Health and Quality of Life Outcomes. 2008; 6(4):1-11. [PubMed: 18179687]

Dennis RE, Boddington SJA, Fennell NJ. Self-report measures of anxiety: Are they suitable for older adults? Aging and Mental Health. 2007; 11(6):668-677. [PubMed: 18074254]

Dion, GA. Unpublished doctoral dissertation. Louisiana State University; New Orleans, Louisiana: 1990. Testing of an instrument to measure acceptance of diabetes: Ideas about Diabetes-Revised (IAD-R).

Dunlop DD, Manheim LM, Sohn M, Liu X, Chang RW. Incidence of functional limitation in older adults: The impact of gender, race, and chronic conditions. Archives of Physical Medicine and Rehabilitation. 2002; 83:964-971. [PubMed: 12098157]

Ferri C, James I, Pruchno R. Successful aging: Definitions and subjective assessment according to older adults. Clinical Gerontologist. 2009; 32:379-388.

Fillenbaum, GG. Multidimensional functional assessment of older adults: The Duke Older Americans Resources and Services procedures. Hillsdale, N. J.: L. Erlbaum Associates; 1988.

Fries, JF. The Health Assessment Questionnaire. In: McDowell, I.; Newell, C., editors. Measuring health: A guide to rating scales and questionnaires. New York: Oxford University Press; 1980/1996.

Haase JE, Britt T, Coward DD, Leidy NK, Penn PE. Simultaneous concept analysis of spiritual perspective, hope, acceptance and self-transcendence. Image: The Journal of Nursing Scholarship. 1992; 24(2):141-147. [PubMed: 1601456]

Hale ED, Treharne GJ, Kitas GD. The Common-Sense Model of self-regulation of health and illness: How can we use it to understand and respond to our patients' needs? Rheumatology. 2007; 46:904-906. [PubMed: 17449488]

Hayes, SC. Content, context, and the types of psychological acceptance. In: Hayes, SC.; Jacobson, NS.; Follette, VM.; Dougher, MJ., editors. Acceptance and change: Content and context in psychotherapy. Reno, N. V.: Context Press; 1994. p. 13-32.

Kaiser HF. An index of factorial simplicity. Psychometrika. 1974; 39:31-36.

Kaplan, GA.; Strawbridge, WJ. Behavioral and social factors in healthy aging. In: Abeles, RP.; Gift, HC.; Ory, MG., editors. Aging and quality of life. New York: Springer Publishing; 1994.

Kintner E. Adolescent process of coming to accept asthma: A phenomenological study. Journal of Asthma. 1997; 34(6):547-561. [PubMed: 9428301]

Ko Y, Coons SJ. An examination of self-reported chronic conditions and health status in the 2001 Medicare health outcomes survey. Current Medical Research and Opinion. 2005; 21(11):18011808. [PubMed: 16307701]

Ledesma RD, Valero-Mora P. Determining the number of factors to retain in EFA: An easy-to-use computer program for carrying out parallel analysis. Practical Assessment Research \& Evaluation. 2007; 12(2):1-11. 
Lee SJ, Moody-Ayers SY, Landefeld CS, Walter LC, Lindquist K, Segal MR, Covinsky KE. The relationship between self-rated health and mortality in older Black and White Americans. Journal of the American Geriatrics Society. 2007; 55(10):1624-1629. [PubMed: 17697102]

Linkowski DC. A scale to measure acceptance of disability. Rehabilitation Counseling Bulletin. 1971; 14:236-344.

McDonald PE, Wykle ML, Misra R, Suwonnaroop N, Burant CJ. Predictors of social support, acceptance, health-promoting behaviors, and glycemic control in African-Americans with type 2 diabetes. Journal of National Black Nurses Association. 2002; 13(1):23-30.

McDonald PE, Zauszniewski JA, Bekhet A. Cultural comparison of chronic conditions, functional status, and acceptance in older African-American and White adults. Journal of the National Black Nurses Association. 2010; 21(1):1-6. [PubMed: 20857770]

Miller RR, Zhang Y, Silliman RA, Hayes MK, Leveille SG, Murabito JM, Kiel D, O'Connor GT, Felson DT. Effect of medical conditions on improvement in self-reported and observed functional performance of Elders. Journal of the American Geriatrics Society. 2004; 52(2):217-223. [PubMed: 14728630]

Mui AC, Burnette D, Chen LM. Cross-cultural assessment of geriatric depression: A review of the CES-D and the GDS. Journal of Mental Health and Aging. 2001; 7:137-164.

Nunnally, JC.; Bernstein, IH. Psychometric theory. 3. New York: McGraw Hill; 1994.

Pfeiffer E. A short portable mental status questionnaire for the ssessment of organic brain deficit in elderly patients. Journal of the American Geriatrics Society. 1975; 23(10):433-441. [PubMed: 1159263]

Radloff LS. The CES-D Scale: A self-report depression scale for research in the general population. Applied Psychological Measurement. 1977; 1(3):385-401.

Ranzijn R, Luszcz M. Acceptance: A key to well-being in older adults. Australian Psychologist. 1999; 34(2):94-98.

Richardson A, Adner N, Nordstrom G. Persons with insulin- dependent diabetes mellitus: Acceptance and coping ability. Journal of Advanced Nursing. 2001; 33(6):758-763. [PubMed: 11298213]

Roe B, Whattam M, Young H, Dimond M. Elders' perceptions of formal and informal care: Aspects of getting and receiving help for their activities of daily living. Journal of Clinical Nursing. 2001; 10:398-405. [PubMed: 11820550]

Silverman M, Nutini J, Musa D, Schoenberg NE, Albert SM. "Is it half full or half empty?" Affective responses to chronic illness. Journal of Cross Cultural Gerontology. 2009; 24(3):291-306. [PubMed: 19340567]

Spielberger, C. Manual for state-trait anxiety inventory. Palo Alto: Consulting Psychologists Press; 1983.

Staab, AS.; Hodges, LC. Essentials of gerontological nursing: Adaptation to the aging process. Philadelphia: J. B. Lippincott Co; 1996.

Strickland OL. Using factor analysis for validity assessment: Practical considerations. Journal of Nursing Measurement. 2003; 11(3):203-205. [Editorial]. [PubMed: 15633776]

Stuifbergen A, Blozis S, Beal C. Conceptualization and development of the acceptance of chronic health conditions scale. Issues in Mental Health Nursing. 2008; 29:101-114. [PubMed: 18293219]

Stuifbergen AK, Rogers S. Health promotion: An essential component of rehabilitation for persons with chronic disabling condition. Advances in Nursing Science. 1997; 19(4):1-20. [PubMed: 9161672]

Telford, K.; Kralik, D.; Koch, T. Integrative Literature Reviews and Meta-analyses. Blackwell Publishing Ltd; 2006. Acceptance and denial: Implications for people adapting to chronic illness: Literature Review; p. 457-464.

Wagner EH, Austin BT, Davis C, Hindmarsh M, Schaefer J, Bonomi A. Improving chronic illness care: translating evidence into action. Medicine \& Chronic Illness. 2001; 20(6):64-78.

Wolff J, Starfield B, Anderson G. Prevalence, expenditures, and complications of multiple chronic conditions in the elderly. Archives of Internal Medicine. 2002; 162(20):2269-2276. [PubMed: 12418941]

Zauszniewski JA. Development and testing of a measure of depressive cognitions in older adults. Journal of Nursing Measurement. 1995; 3(1):31-41. [PubMed: 7493187] 
Zauszniewski JA. The Depressive Cognition Scale: Further psychometric evaluation. Journal of Nursing Measurement. 1997; 5(2):191-200. [PubMed: 9538590]

Zauszniewski JA, Bekhet AK. Depressive symptoms in elderly women with chronic conditions: Measurement issues. Aging and Mental Health. 2009; 13(1):64-72. [PubMed: 19197691]

Zauszniewski JA, Chung C, Krafcik K, Sousa VD. Psychometric testing of the depressive cognition scale in women with type 2 diabetes. Journal of Nursing Measurement. 2001; 9(1):61-72. [PubMed: 11469143]

Zauszniewski JA, Graham GC. Comparison of short scales to measure depression in elders with diabetes. Western Journal of Nursing Research. 2009; 31(2):219-34. [PubMed: 19050228]

Zauszniewski JA, McDonald PE, Krafcik K, Chung C. Acceptance, cognitions, and resourcefulness in women with diabetes. Western Journal of Nursing Research. 2002; 24(7):728-743. [PubMed: 12428892]

Zauszniewski, JA.; McDonald, PE.; Musil, CM.; DeHelian, L.; Brady, N.; Vealadee, U.; Lai, CY. Effects of Teaching Resourcefulness and Acceptance on Affect, Behavior, and Cognition of Chronically Ill Elders. Proceedings from the National State of the Science Congress in Nursing Research Conference; Washington, DC: Friends of the National Institute of Nursing Research; Oct. 2004 [abstract]

Zauszniewski JA, Morris DL, Preechawong S, Chang HJ. Reports of depressive symptoms in elders with chronic conditions. Research and Theory for Nursing Practice: An International Journal. 2004; 18(2/3):185-196.

Zauszniewski JA, Picot SJ, Debanne SM, Roberts BL, Wykle ML. Psychometric characteristics of the Depressive Cognition Scale in African American women. Journal of Nursing Measurement. 2002; 10(2):83-95. [PubMed: 12619530] 
Scree Plot Supporting the Selection of Three Factors

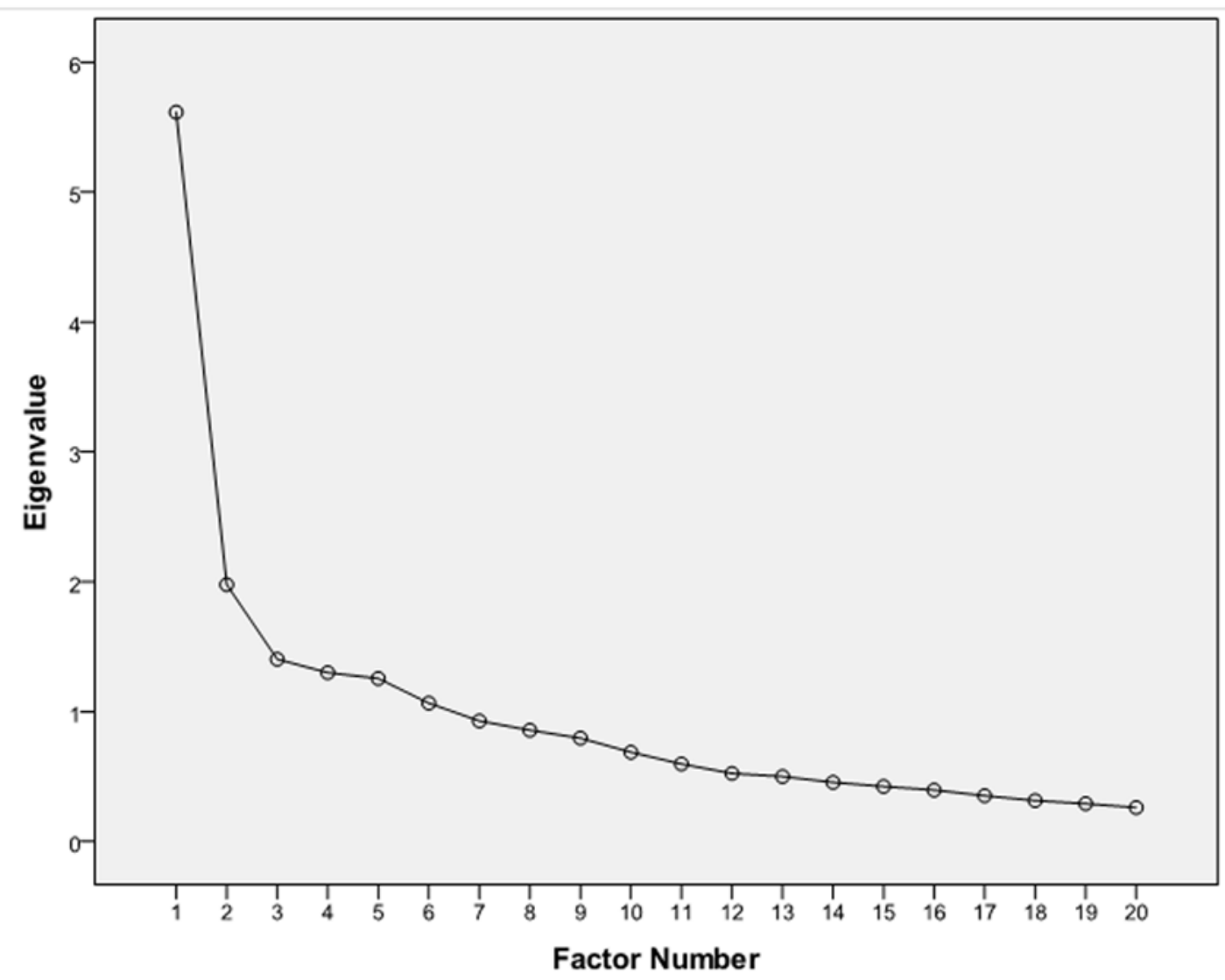

Figure 1. 


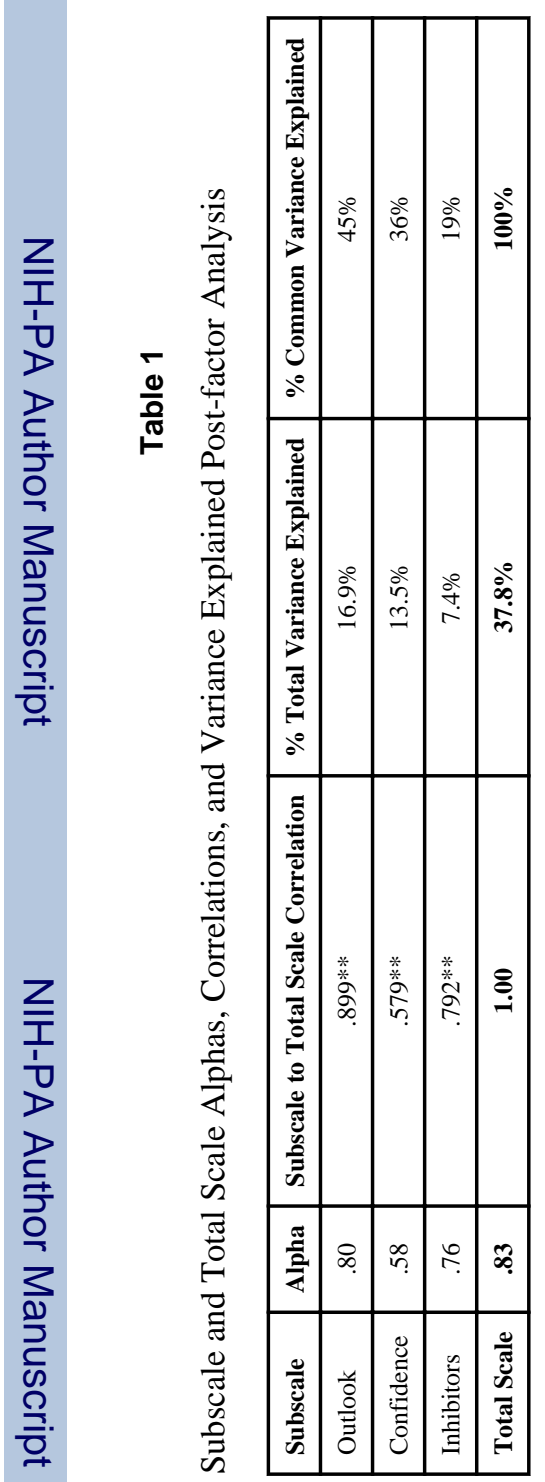


Table 2

Item to Total Scale and Item to Subscale Correlations

\begin{tabular}{|c|c|c|c|c|}
\hline Item & Item Description & Item to Total Scale Correlation & Predicted Subscale & Item to Subscale Correlation \\
\hline 1 & Hopeful about future & $.467^{* *}$ & Outlook & $.557^{* *}$ \\
\hline 2 & Not tell others about health problems & .104 & None & $\mathrm{n} / \mathrm{a}$ \\
\hline 3 & Less satisfied with life than others & $.693^{* * *}$ & Outlook & $.691^{* *}$ \\
\hline 4 & Comfort talking with others & $.323^{* *}$ & Confidence & $.776^{* *}$ \\
\hline 5 & Can do like others without problems & $.587^{* *}$ & Outlook & $.657^{* *}$ \\
\hline 6 & Important to care for health problems & $.318^{* * *}$ & Confidence & $.358^{* *}$ \\
\hline 7 & People not invite me & $.577^{* * *}$ & Inhibitors & $.715^{* *}$ \\
\hline 8 & Not schedule life around medical & $.204^{* * *}$ & Inhibitors & $.337^{* *}$ \\
\hline 9 & Lead full and productive life & $.715^{* * *}$ & Outlook & $.795^{* *}$ \\
\hline 10 & Expect to be healthy for long & $.662^{* *}$ & Outlook & $.743^{* *}$ \\
\hline 11 & Talk about health problems & .081 & Confidence & $.447^{* *}$ \\
\hline 12 & Follow medical plan & $.613^{* * *}$ & Confidence & $.529^{* *}$ \\
\hline 13 & Not have many good things & $.668^{* * *}$ & Inhibitors & $.780^{* *}$ \\
\hline 14 & Ease in talking about health problems & $.302^{* * *}$ & Confidence & $.715^{* * *}$ \\
\hline 15 & Not able to lead normal life & $.668^{* * *}$ & Inhibitors & $.807^{* *}$ \\
\hline 16 & Health problems not affect social life & $.626^{* *}$ & Outlook & $.717^{* *}$ \\
\hline 17 & Follow Dr.'s orders for good health & $.507^{* * *}$ & Confidence & $.497^{* *}$ \\
\hline 18 & Would have more friends if healthy & $.471^{* * *}$ & Inhibitors & $.673^{* *}$ \\
\hline 19 & Health problems prevent activities & $.557^{* *}$ & Inhibitors & $.694^{* *}$ \\
\hline 20 & Health problems not affect others & $.477^{* * *}$ & Outlook & $.548^{* *}$ \\
\hline
\end{tabular}

**

$\mathrm{p}<.01$ 


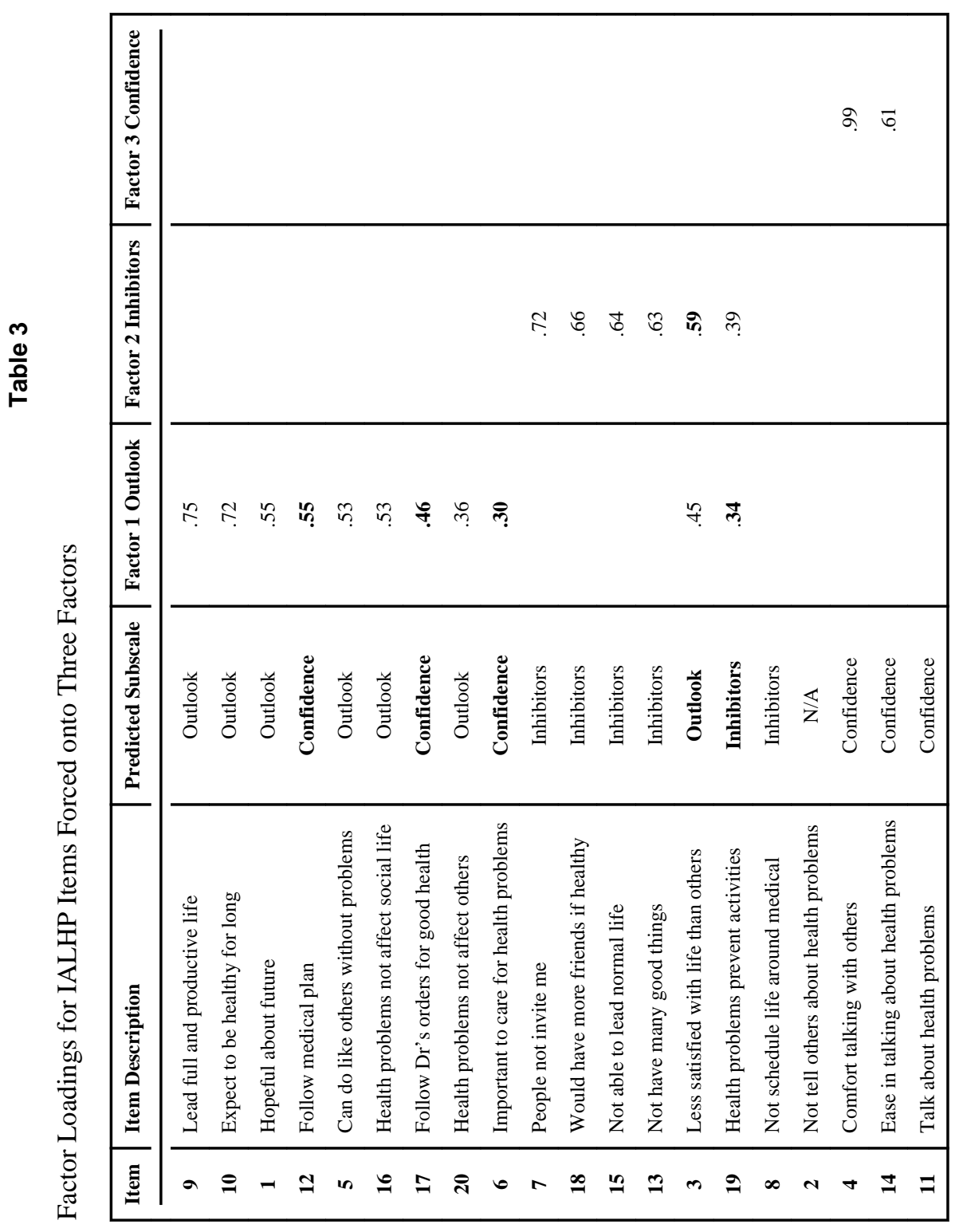

Issues Ment Health Nurs. Author manuscript; available in PMC 2012 September 26. 
Table 4

IALHP Scale Correlations with Measures of Theoretically-related Constructs

\begin{tabular}{|l|l|l|}
\hline Construct & Measure & Correlation \\
\hline Self-assessed health & Three self-rated items & $\mathrm{r}=.53, \mathrm{p}<.001$ \\
\hline Functional status & Health Assessment Questionnaire-Disability Index (HAQ-DI) & $\mathrm{r}=-.53, \mathrm{p}<.001$ \\
\hline Anxiety & State Anxiety Inventory (STAI A-State) & $\mathrm{r}=-.39, \mathrm{p}<.001$ \\
\hline Depression & Center for Epidemiological Studies- Depression Scale (CES-D) & $\mathrm{r}=-.44, \mathrm{p}<.001$ \\
\hline Positive cognitions & Depressive Cognitions Scale (DCS) & $\mathrm{r}=.61, \mathrm{p}<.001$ \\
\hline
\end{tabular}

